\title{
Evaluating the Impact of ACLS Scenario Based Resuscitation Simulation for Emergency Team
}

\section{Yogendra Amatya ${ }^{1}$ and Susmita Shrestha ${ }^{2}$}

${ }^{1}$ Department of General Practice and Emergency Medicine, Patan Academy of Health Sciences, Lalitpur, Nepal ${ }^{2}$ Audiology and Speech Language Pathology Unit, Department of ENT-HNS, TUTH, MMC, Institute of Medicine, Kathmandu, Nepal

\begin{abstract}
Introduction: Medical simulation has become increasingly important for education in emergency situations like resuscitation and improvising healthcare services.

Methods: A prospective study was performed implementing ACLS resuscitation simulation with the Patan Hospital emergency team. The survey questionnaire was designed to evaluate participants' communication skills, leadership, team dynamics, competency in ACLS and perception regarding simulation as a learning method. The paired t-tests were performed to compare pre and post simulation survey responses. The quantitative data were managed and analysed using Microsoft Excel.

Results: Fifty seven emergency staffs participated in the study. In the communication domain presimulation survey mean likert score of close loop communication was 2.68, SBAR was 2.54 and PEARL was 2.25 while the post-simulation survey were $3.19,3.05$ and 2.96 respectively. In leadership pre-survey assessment of coordinating team members was 2.61 and summarising events skill was 2.58 while the post-survey scores were 2.91 and 3.02 respectively. The team dynamics pre-survey of the teamwork experience was 2.63 while post-survey was 3.07 . The competency pre-survey of competency level in ACLS was 2.51 while the post-survey was 2.88 . The pre-survey regarding considering simulation a good method of training was 3.32 while the post-survey was 3.56. All the survey questionnaires of each domain showed the increased difference that is statically significant with $p$-values $<0.001$.

Conclusions: Simulation training is an effective and useful educational technique for training the health personnel working in emergency service.
\end{abstract}

Key words: communication; competency; leadership; resuscitation; simulation; teamwork

Correspondence: Susmita Shrestha, Audiology and Speech Language Pathology Unit, Department of ENT-HNS, TUTH, MMC, IOM, Kathmandu, Nepal. Email id: sushmitaiom@gmail.com

DOI: $10.3126 / \mathrm{mjsbh} . v 20 \mathrm{i} 1.31431$

Submitted on: 2020-09-23

Accepted on: 2021-01-09

This work is licensed under creative common license:

http://creativecommons.org/licenses/by-nc-nd/4.0/ C MJSBH 2020 


\section{INTRODUCTION}

Simulations represent approximately exact replication of tasks, knowledge, skills, and abilities required in real work behaviour. ${ }^{1}$ High-fidelity medical simulation has become increasingly important for education in emergency situations like resuscitation and improvising healthcare services in most of the developed part of the world. ${ }^{2-4}$ It allows teaching of theoretical knowledge along with improvement of the handson skills of rescuers without harming patients in a safe environment. ${ }^{2,5-7}$

In Nepal the use of simulation practice has been limited to trainings like PALS, PTC, ACLS and ATLS. Although this method of training has got outstanding feedback, it is rarely used in our medical institutes including PAHS. There has not been any study performed regarding use of medical simulation in the medical institute of Nepal in the past. As the simulation has become one of the important methods for providing education regarding emergency situation, this study was conducted to evaluate the impact of case based simulation on skill relating to communication, leadership, teamwork and overall competency for emergency team of Patan Hospital and assess attitudes toward the use of simulation among the participants.

\section{METHODS}

A prospective cross sectional study was performed implementing ACLS case based resuscitation simulation for the emergency team of Patan Hospital. This was conducted at the Patan Hospital skill lab from August to November 2016. A convenience sample of 57 emergency team members including doctors (Faculties, House officers, Residents, Interns) and nurses working in emergency was consented for participation.

The structure of each simulation session included:

- Pre-briefing of the simulation. (15mins)

- Pre-simulation survey form. Attached in Annex 1(5 mins)

- ACLS case based resuscitation simulation performed. Attached in Annex 2 (30 mins)

- Debriefing using PEARLS script method. Attached in Annex 3 (15mins)

- Post-simulation survey form. Attached in Annex 4 (5 mins)
The simulation session had minimum of six participants at one session as per the guidelines given by ACLS for resuscitation ${ }^{8}$ and lasted for one to one and half hours. During pre-briefing, participants were educated using power-point presentation and video presentation of running ACLS megacode regarding communication skills, leadership skill, teamwork skill and overall competency of performing ACLS scenario. Participant questions were addressed during this period.

Regarding communication skills the participants were explained about closed loop communication, ${ }^{9}$ SBAR (Situation, Background, Assessment and Recommendation) communication ${ }^{10}$ and PEARLS (Promoting Excellence and Reflective Learning in Simulation $)^{11}$ method of debriefing. Leadership skills were discussed on aspect of qualities making a good leader, coordinating the team members, summarizing the events during resuscitation, showing situational awareness and sharing the knowledge among team members. Teamwork skills were focused on the importance of team structure, individual roles (identification of leader, roles of intravenous / intraosseous care, recorder, monitor, airway management and compressor) and the team dynamics. Competency was defined as the levels of competency in running ACLS megacode and was categorized as needs remediation, passed (meets minimum standards) and instructor potential (excels in all areas).

The survey questionnaire was designed to evaluate participants' communication skill, leadership, team dynamics, competency in ACLS and perception regarding simulation as a teaching learning method. Text was aligning with pre/post nature of the study. We used a paper survey to gather data from participants. Basic demographic information was collected. In addition, the pre and post survey questionnaires each contained 8 identical four-point Likert scale questions (Excellent $=4$, Good $=3$, Poor $=2$ and Very Poor $=1$ ). The post simulation survey contained an additional one question with four-point Likert scale.

After the pre-briefing session participants were given pre-simulation survey form to complete. Following which they were given ACLS case based resuscitation scenario to run a simulation using 
CPR manikin and other resuscitation supplies including Sim-mon application installed I-pad as a monitor. The same ACLS scenario was used for all the participants. ${ }^{8}$ Debriefing using PEARLS script method was done immediately among the participants and the researcher. Finally at the end of session the post-simulation survey was given to all the participants to complete. The study included all the doctors, residents, interns and nurses working in emergency during the period of study. The emergency staffs that were not involved in resuscitation were excluded from the study. Initially the sample size was estimated around 100 in total but only 57 participants were involved as per their convenience time.

This study was done in partnership with Patan Hospital Emergency Department and with the approval of Patan Hospital's ethical Institutional Review Committee. Verbal consent was taken from all the participants. Response categories were either categorical (gender, designation etc.) or based on the above 4-point likert-scale. We included a single open-ended question to obtain qualitative feedback on the participant's experience and on improvement of simulation. We calculated descriptive statistics for demographics and responses to survey questionnaires. We performed paired t-tests to compare pre- and post-simulation survey responses from the participants. The quantitative data were managed and analysed using Microsoft excel. P values of less than 0.05 were considered as significant.

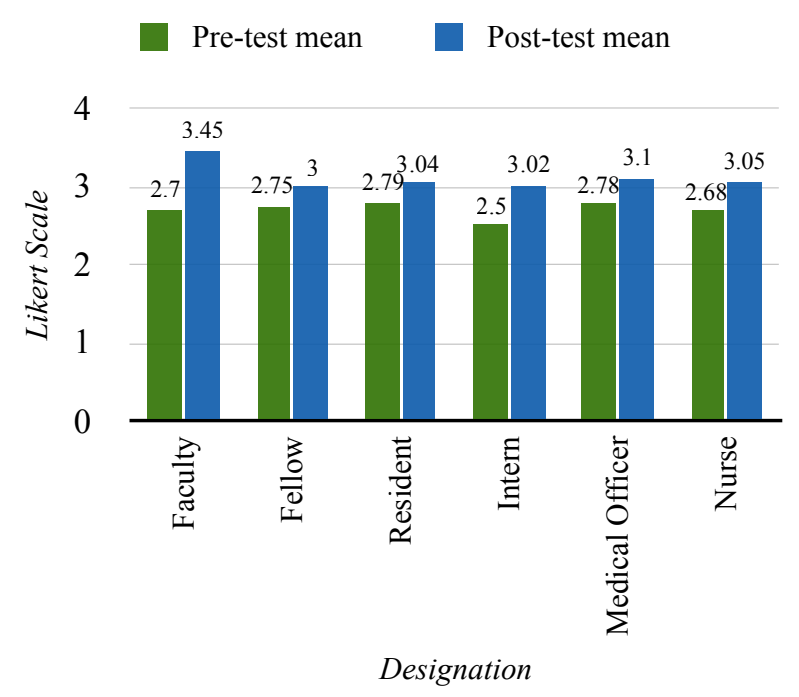

Figure 1. Pre- and Post-Test Scores by Designation

\section{RESULT}

Fifty-seven emergency staff participated in the study. All the participants completed pre-survey and post-survey questionnaires. Participants' ages found to be averaged $27.17 \pm 4.45$ years. Fifty six percent were males while $44 \%$ of total participant were females. On designation demographic, $91 \%$ of participants were doctors while $9 \%$ of total participants were nurses. Regarding the prior experience of simulation, $51 \%$ had no any experience while 49 had some sort of experience (Table 1).

In the communication domain the pre-simulation survey mean likert score of close loop communication skills was 2.68 [ \pm SD 0.51], SBAR skills was 2.54 [ \pm SD 0.57] and PEARL skills was 2.25 [ \pm SD 0.54$]$ while the post-simulation survey mean likert score were 3.19 [ \pm SD 0.52], $3.05[ \pm$ SD 0.48] and 2.96 [ \pm SD 0.42] respectively. All the survey questionnaires of communication domain showed the increased difference, with a p-value $<$ 0.001 (Table 2). Also in the leadership domain the pre-simulation survey mean likert score of coordinating team members skill was $2.61[ \pm \mathrm{SD}$ $0.53]$ and summarising events skill was 2.58 [ \pm SD 0.60 ] while the post-simulation survey mean likert score were $2.91[ \pm$ SD 0.54] and $3.02[ \pm$ SD 0.48] respectively. Both the survey questionnaires of leadership domain showed the increased difference with a p-value $<0.001$. Likewise in the team dynamics domain the pre- simulation survey mean likert score of the teamwork experience was $2.63[ \pm$

Table 1. Demographics

\begin{tabular}{|c|c|c|}
\hline \multicolumn{2}{|l|}{ Parameters } & n $(\%)$ \\
\hline \multicolumn{2}{|l|}{ Total Participants } & 57 \\
\hline \multicolumn{2}{|l|}{ Age } & $27.17 \pm 4.45$ \\
\hline \multirow[t]{2}{*}{ Gender } & Male & $32(56)$ \\
\hline & Female & $25(44)$ \\
\hline \multirow[t]{6}{*}{ Designation: } & Faculty & $5(9)$ \\
\hline & Fellow & $1(2)$ \\
\hline & MDGP Resident & $7(12)$ \\
\hline & Medical Officer & $14(24)$ \\
\hline & Intern & $25(44)$ \\
\hline & Nurse & $5(9)$ \\
\hline \multirow[t]{2}{*}{ Prior Experience } & Yes & $28(49)$ \\
\hline & No & $29(51)$ \\
\hline
\end{tabular}


Table 2. Pre- and post - simulation survey Mean Likert Score responses

\begin{tabular}{|c|c|c|c|c|c|}
\hline & Questionnaires & $\begin{array}{l}\text { Pre-Test } \\
\text { Mean (SD) }\end{array}$ & $\begin{array}{l}\text { Post-Test } \\
\text { Mean (SD) }\end{array}$ & Difference & p-Value \\
\hline \multirow[t]{3}{*}{ Communication } & $\begin{array}{l}\text { 1.Please rate your close loop } \\
\text { communication skills in the management } \\
\text { of critically ill patients }\end{array}$ & $2.68(0.51)$ & $3.19(0.52)$ & 0.51 & $<0.001$ \\
\hline & $\begin{array}{l}\text { 2. Please rate your SBAR skills in the } \\
\text { management of critically ill patients }\end{array}$ & $2.54(0.57)$ & $3.05(0.48)$ & 0.51 & $<0.001$ \\
\hline & $\begin{array}{l}\text { 3. Please rate your PEARL skills for } \\
\text { debriefing in the management of } \\
\text { critically ill patients }\end{array}$ & $2.25(0.54)$ & $2.96(0.42)$ & 0.71 & $<0.001$ \\
\hline \multirow[t]{2}{*}{ Leadership } & $\begin{array}{l}\text { 4. Please rate your skills in coordinating } \\
\text { team members in managing critically ill } \\
\text { patients. }\end{array}$ & $2.61(0.53)$ & $2.91(0.54)$ & 0.30 & $<0.001$ \\
\hline & $\begin{array}{l}\text { 5. Please rate your skills in summarizing } \\
\text { events while managing critically ill } \\
\text { patients. }\end{array}$ & $2.58(0.60)$ & $3.02(0.48)$ & 0.44 & $<0.001$ \\
\hline Team Dynamics & $\begin{array}{l}\text { 6. Please rate your experience in the } \\
\text { teamwork in the management of } \\
\text { critically ill patients. }\end{array}$ & $2.63(0.56)$ & $3.07(0.50)$ & 0.44 & $<0.001$ \\
\hline Competency & $\begin{array}{l}\text { 7. Please rate your competency level in } \\
\text { treating a patient requiring advanced } \\
\text { cardiovascular life support (ACLS). }\end{array}$ & $2.51(0.57)$ & $2.88(0.47)$ & 0.37 & $<0.001$ \\
\hline Simulation & $\begin{array}{l}\text { 8. Please rate how good of a method you } \\
\text { consider simulation training to practice/ } \\
\text { reinforce your teamwork skills. }\end{array}$ & $3.32(0.63)$ & $3.56(0.54)$ & 0.24 & $<0.007$ \\
\hline
\end{tabular}

SD 0.56] while the post-simulation survey mean likert score was 3.07 [ \pm SD 0.50]. The team dynamic domain showed the increased difference with a p-value $<0.001$. Similarly in the competency domain the pre- simulation survey mean likert score of the competency level in ACLS was 2.51 [ \pm SD 0.57] while the post-simulation survey mean likert score was 2.88 [ \pm SD 0.47]. The competency domain showed the increased

Table 3. Pre- and Post-Simulation Mean Likert Scores by Designation

\begin{tabular}{|l|r|r|r|r|}
\hline $\begin{array}{l}\text { Designati } \\
\text { on }\end{array}$ & $\begin{array}{l}\text { Pre- } \\
\text { Simulation } \\
\text { Mean }\end{array}$ & $\begin{array}{l}\text { Post- } \\
\text { Simulation } \\
\text { Mean }\end{array}$ & \multicolumn{1}{l}{$\begin{array}{l}\text { Differenc } \\
\text { value }\end{array}$} \\
\hline Faculty & 2.70 & 3.45 & 0.75 & $<0.001$ \\
\hline Fellow & 2.75 & 3.00 & 0.25 & 0.351 \\
\hline $\begin{array}{l}\text { MDGP } \\
\text { Resident }\end{array}$ & 2.79 & 3.04 & 0.25 & 0.003 \\
\hline $\begin{array}{l}\text { Medical } \\
\text { Officer }\end{array}$ & 2.78 & 3.10 & 0.32 & $<0.001$ \\
\hline Intern & 2.50 & 3.02 & 0.52 & $<0.001$ \\
\hline Nurse & 2.68 & 3.05 & 0.37 & $<0.002$ \\
\hline
\end{tabular}

difference with a p-value $<0.001$. Finally in the simulation domain the pre-simulation survey mean likert score of simulation considered as a good method of training was 3.32 [ \pm SD 0.63] while the post-simulation survey mean likert score was 3.56 [ \pm SD 0.54]. The simulation domain showed the increased difference with a $p$-value $=0.007$ (Table 2).

In respect of designation categories, Faculty, MDGP Residents, Medical Officer, Intern and Nurse all showed the difference value between presimulation and post-simulation as a statistically significant with a p-value $<0.001$ in Faculty, Medical officer, Intern while a $\mathrm{p}$-value $=0.003$ in MDGP Resident and a $p$-value $=0.002$ in Nurse

Table 4. The realism of the simulated environment

\begin{tabular}{|l|r|r|}
\hline & Frequency & \multicolumn{2}{|c|}{ Percentage } \\
\hline Excellent & 14 & 24.5 \\
\hline Good & 42 & 73.8 \\
\hline Poor & 1 & 1.7 \\
\hline Very Poor & 0 & 0 \\
\hline
\end{tabular}


category respectively. In the Fellow category the difference value was not statically significant (Table 3).

The post-simulation surveys mean likert score of all the categories of the designation as in Faculty, Fellow, MDGP Residents, Medical Officer, Intern and Nurse had showed increased than the presimulation surveys mean likert score (Figure 1). Regarding the survey question about the realism of the simulated environment, $73.8 \%$ had responded as good, $24.5 \%$ had responded as excellent while $1.7 \%$ had responded as poor (Table 4 ).

\section{DISCUSSION}

The study has shown a noticeable improvement in all the five domains namely communication, leadership, team dynamics, competency and simulation respectively in post-simulation survey in comparison to pre-simulation survey.

In the communication domain, all three questionnaires relating to closed loop communication, SBAR and PEARL skills, participant's demonstrated statistically significant improvement. Although these communication skills mentioned in some trainings happening in Nepal, these skills are not commonly practiced during resuscitation or in other clinical use. One session of simulation has markedly increased their orientation and confidence in using these skills.

Similarly in the leadership domain, the postsimulation survey has shown better outcome with statistical significance in both aspect of coordinating the team members and summarising the events during resuscitation. Both are essential qualities of being a good team leader in running a resuscitation code. Regarding team dynamics, the study has increased participants' experience of team-work in resuscitation. A study done by Lerner et al. in 2009 mentioned that a well-functioning team should be able to do things more effectively and safely than an individual or a group of individuals while a poorly functioning team, however, may be antagonistic and detrimental to productivity. ${ }^{12}$

The simulation has increased the capacity to work as a member of the team and coordinating the team is an essential part for better outcome of resuscitation. Previous researches like by Hunziker et al. in 2011 has shown that a prolonged process of team building and poor leadership behaviour are associated with significant shortcomings in resuscitation procedure like CPR on the other hand teamwork and leadership training have been shown to improve subsequent team performance during resuscitation and have recently been included in guidelines for advanced life support courses. ${ }^{2}$

The competency of performing ACLS coded case has increased in post-simulation in compare to presimulation with statically significance. As our simulation session is relating with ACLS case scenario, after taking part in the session, most of the participants have gained confidence in handling such case. Simulation can increase the competency level in any competency-based skill.

In 2016, the study done by Cartier et al. in Switzerland also has shown the effectiveness in improving short and long term competency and knowledge of CVC insertion by using simulation based medical educational training. ${ }^{13}$ The perspective of participation regarding the simulation as a good method for learning a team work skills during the resuscitation has found to be more positive responded after post-simulation. Many studies like Okuda et al. 2008 has shown that high-fidelity mannequin simulation appears to have the most promise in the training of physicians and may affect true patient outcome. ${ }^{14}$ Also study done by Perkins in 2007 concluded that simulation plays a central role in contemporary advanced life support training and aims to provide health care professionals with the responsibility for managing cardiac arrests with the necessary knowledge, attitudes and skills to effectively deal with this condition in a structured and systematic manner. ${ }^{6}$ In our study also with the post-simulation responses showing that simulation can be a great method for teaching and learning medical case scenarios, skills like CPR, tracheal intubation, LMA insertion, needle and surgical cricothyroidotomy, peripheral cannulation \& central venous catheter, chest drain insertion, ACLS ECG rhythm recognition, defibrillation, and cardiac pacing.

This study demonstrated effectiveness of simulation for various levels of providers, including nurses, interns, residents and faculty. While the fellow group was not significantly improved, this 
was possibly due to a low sample size with only one candidate in that group. Therefore, we acknowledge simulation as a good method of education for different levels of academic qualification to help in communication, leadership, team dynamics and increasing knowledge and resuscitation competency. Shapiro et al. 2010 also highlighted that teamwork training conducted within the simulated environment may offer an additive benefit to the traditional textbook teaching method, enhance performance and possibly reduce medical error. ${ }^{15}$

Regarding the realism of the performed simulated environment, about $98 \%$ of the participants have given positive response as good and excellent. Although running simulation in this PAHS academic institution is quite a new experience, this positive feedback will definitely encourage the health personnel for running such type of simulation sessions. Moreover most of the participants have suggested for continuing this kind of simulation session more often.

Our research however has some limitations. The sample size and the sampling are done in a convenient way which may affect the result of the study. The same instructor being each time does also affect the study analysis. The pre-simulation and post-simulation surveys were done without a control group. Also there is no inter-observer comparison group as it is a self assessment survey. Despite all these limitations the conclusions of this study can be useful for generating hypothesis on whether the intervention is useful or not.

\section{CONCLUSIONS}

The standardisation of simulation to train and maintain skills used in ACLS may improve care given in critical clinical scenarios like resuscitations by improving essential qualities like communication skills, leadership, team dynamics and competency. Hence simulation training is an effective and useful educational technique for training the health personnel working in emergency service. We should strive to make simulation of crises scenarios an important and necessary module in training future undergraduates and postgraduates curriculum. This would allow team work and assessment of competency in a controlled and safe environment. Further research is therefore needed to define the effects of team interactions on performance of complex medical crisis management. Thereby, through further investigation, the influence of individual factors, team factors and external factors (e.g. equipment, algorithms, institutional characteristics) on team performance in resuscitation situations are critical future areas for investigation.

\section{ACKNOWLEDGE}

I express my gratitude to Dr Ashis Shrestha and Dr Darlene Rose House for their guidance in statistical analysis.

To cite this article: Amatya Y, Shrestha S. Evaluating the Impact of ACLS Scenario Based Resuscitation Simulation for Emergency Team. MJSBH. 2021;20(1):12-8.

Conflict of Interest: None declared

\section{REFERENCES}

1. Lievens F, De Soete B. Simulations. Handbook of Assessment and Selection. 2012;20:383-410. DOI: https:// doi.org/10.1093/oxfordhb/9780199732579.013.0017

2. Hunziker S, Johansson A, Tschan F, Semmer N, Rock L, Howell M, et al. Teamwork and Leadership in Cardiopulmonary Resuscitation. JACC. 2011;57(24):2381-8. DOI: 10.1016/j.jacc.2011.03.017.

3. Bhanji F, Mancini M, Sinz E, Rodgers D, McNeil M, Hoadley T, et al. Part 16: Education, Implementation, and Teams: 2010 American Heart Association Guidelines for Cardiopulmonary Resuscitation and Emergency Cardiovascular Care. Circulation. 2010;122(18):920-33. DOI: https://doi.org/10.1161/CIRCULATIONAHA. 110.971135 
4. Soar J, Mancini M, Bhanji F, Billi J, Dennett J, Finn J, et al. Part 12: Education, implementation, and teams. Resuscitation. 2010;81(1):288-332. DOI: 10.1016/j.resuscitation.2010.08.030

5. Soar J, Monsieurs K, Ballance J, Barelli A, Biarent D, Greif R, et al. European Resuscitation Council Guidelines for Resuscitation 2010 Section 9. Principles of education in resuscitation. Resuscitation. 2010;81(10):1434-44. DOI: https://doi.org/10.1016/j.resuscitation.2010.08.014

6. DeVita M. Improving medical emergency team (MET) performance using a novel curriculum and a computerised human patient simulator. Qual Saf Health Care. 2005;14(5):326-31. DOI: 10.1136/qshc.2004.011148

7. Perkins G. Simulation in resuscitation training. Resuscitation. 2007;73(2):202-11. DOI: https://doi.org/10.1016/ j.resuscitation.2007.01.005

8. American Heart Association. Advanced Cardiovascular Life Support: Instructor's Manual. American Hearth Association; 2011;64-5.

9. Härgestam M, Lindkvist M, Brulin C, Jacobsson M, Hultin M. Communication in interdisciplinary teams: exploring closed-loop communication during in situ trauma team training. BMJ Open. 2013;3(10):003525. DOI: 10.1136/ bmjopen-2013-003525

10. Thomas CM, Bertram E, Johnson D. The SBAR communication technique: teaching nursing students professional communication skills. Nurse Educ. 2009;34(4):176-80. DOI: 10.1097/NNE.0b013e3181aaba54

11. Eppich W, Cheng A. Promoting Excellence and Reflective Learning in Simulation (PEARLS): development and rationale for a blended approach to health care simulation debriefing. Simul Healthc. 2015;10(2):106-15. DOI: 10.1097/SIH.0000000000000072

12. Lerner S, Magrane D, Friedman E. Teaching Teamwork in Medical Education. Mt Sinai J Med. 2009;76(4):318-29. DOI: https://doi.org/10.1002/msj.20129

13. Cartier V, Inan C, Zingg W, Delhumeau C, Walder B, Savoldelli G. Simulation-based medical education training improves short and long-term competency in, and knowledge of central venous catheter insertion. EJA. 2016;33(8): 568-74. DOI: 10.1097/EJA.0000000000000423

14. Okuda Y, Quinones J. The use of simulation in the education of emergency care providers for cardiac emergencies. Int J Emerg Med. 2008;1(2):73-7. DOI: 10.1007/s12245-008-0034-2

15. Shapiro M, Morey J, Small S, Langford V, Kaylor C, Jagminas L. Simulation based teamwork training for emergency department staff: does it improve clinical team performance when added to an existing didactic teamwork curriculum?. Qual Saf Health Care. 2004;13(6):417-21. DOI: 10.1136/qshc.2003.005447 